\title{
ACESSO À JUSTIÇA COMO DIREITO HUMANO FUNDAMENTAL: JUSTIÇA MULTIPORTAS E RESTAURATIVA
}

\section{ARTIGO ORIGINAL}

BARBOSA, André Luciano ${ }^{1}$, MATSUSHITA, Thiago Lopes ${ }^{2}$

BARBOSA, André Luciano. MATSUSHITA, Thiago Lopes. Acesso à justiça como direito humano fundamental: justiça multiportas e restaurativa. Revista Científica Multidisciplinar Núcleo do Conhecimento. Ano 06, Ed. 08, Vol. 05, pp. 36 50. Agosto de 2021. ISSN: 2448-0959, Link de acesso: https://www.nucleodoconhecimento.com.br/lei/multiportas-e-restaurativa, $\quad$ DOI: 10.32749/nucleodoconhecimento.com.br/lei/multiportas-e-restaurativa

\section{RESUMO}

O presente artigo tem como eixo central tratar da conciliação e da justiça restaurativa como métodos adequados de Acesso à Justiça, para tanto, irá desenvolver o tema da Justiça Multiportas em seu sentido amplo. Tem como questão norteadora responder o que pode ser aperfeiçoado nos aspectos estruturais, processuais e humanitários, para fins de ampliação de seus efeitos práticos. Incialmente, se desmistifica a ideia do Poder Judiciário como provedor único de Justiça entre as partes. Em seguida, os métodos de conciliação, mediação, arbitragem e justiça restaurativa, mormente esta última, serão trabalhados. Estes métodos traduzem direitos humanos fundamentais, na medida em que ampliam o Acesso à Justiça em seu sentido amplo, isto é, uma Justiça que transborda os limites do Poder Judiciário. A metodologia utilizada nas construções e reflexões deste artigo é a bibliográfica, explicativa e descritiva, com pesquisa em livros da área jurídica especializada, sem abandonar os métodos indutivos e dedutivos. Por fim,

\footnotetext{
${ }^{1}$ Mestrando em Direito pela PUC-SP, Especialista em Direito Administrativo pela PUC-SP, Especialista em Direito Privado pela Escola Paulista da Magistratura, Bacharel em Direito pela PUC-SP.

${ }^{2}$ Doutorado em Direito. Orientador.
}

$\mathrm{RC}: 94657$

Disponível em: https://www.nucleodoconhecimento.com.br/lei/multiportas-erestaurativa 
apresentou-se conclusões sobre a necessidade de ampliação prática dos institutos tratados, alargando as matérias que podem ser por eles tratadas e, principalmente, abrindo espaço para as partes, verdadeiros atores do conflito, para que busquem, por meio dos diversos métodos adequados à solução de controvérsia, a melhor forma de solucionar o impasse colocado.

Palavras-chave: Direitos Fundamentais, Acesso à justiça, Métodos adequados, Justiça Restaurativa.

\section{INTRODUÇÃO}

Ao longo deste artigo será desenvolvida e aprofundada a temática dos métodos alternativos (adequados) de resolução de conflito, não só no aspecto legal, mas também, e principalmente, nas questões psicológicas que envolvem esse novo movimento de acesso à Justiça, ressaltando-se que o acesso à justiça é direito humano fundamental, conforme previsto na Constituição Federal (BRASIL, 1988). assunto é de extrema relevância diante da difícil situação de gestão do Poder Judiciário em termos orçamentários, estruturais, humanos e, em última análise, da qualidade do serviço que é prestado ao jurisdicionado, conforme se pode verificar no periódico do Conselho Nacional de Justiça denominado de "Justiça em números" de 2020.

O presente artigo tem como eixo central os métodos adequados de solução de conflito (conciliação, mediação e arbitragem), bem como a justiça restaurativa. Nesse diapasão, será respondido o que pode ser aperfeiçoado nos aspectos estruturais, processuais e humanitário, para fins de ampliação de seus efeitos práticos. A metodologia fundamental utilizada nas construções e reflexões deste artigo é a bibliográfica, explicativa e descritiva, com ampla pesquisa em livros da área jurídica especializada, sem abandonar os métodos indutivos e dedutivos.

A falência de uma estrutura revela a necessidade de buscar novas práticas para a solução dos conflitos humanos, de todas as naturezas. Desde que se tem notícia da

RC: 94657

Disponível em: https://www.nucleodoconhecimento.com.br/lei/multiportas-erestaurativa 
existência humana se sabe da ocorrência de conflitos, o que varia é a forma com que se lida com ele. O Poder Judiciário é apenas uma maneira de se entregar o "serviço da Justiça", entretanto, existem diversas outras que podem ser utilizadas, não só com o escopo de descomprimir o Judiciário, mas também, e não menos importante, entregar uma melhor resolução ao impasse colocado, para os envolvidos.

Desde logo, deve-se ressaltar que a Justiça é um conceito relativo, com significado inconsistente, oportuna às palavras de Kelsen (2001, p. 25), em seu livro "O que é Justiça?":

Iniciei este ensaio com a questão: o que é justiça? Agora, ao final, estou completamente ciente de não tê-lo respondido. A meu favor, como desculpa, está o fato de que me encontro nesse sentido em ótima companhia. Seria mais do que presunção fazer meus leitores acreditarem que eu conseguiria aquilo em que fracassaram os maiores pensadores. De fato, não sei e não posso dizer o que seja justiça, a justiça absoluta, esse belo sonho da humanidade. Devo satisfazer-me com uma justiça relativa, e só posso declarar o que significa justiça para mim: uma vez que a ciência é minha profissão e, portanto, a coisa mais importante em minha vida, trata-se daquela justiça sob cuja proteção a ciência pode prosperar e, ao lado dela, a verdade e a sinceridade. É a justiça da liberdade, da paz, da democracia, da tolerância. (grifo nosso)

A Justiça como um produto exclusivo do Poder Judiciário precisa ser desmistificada do imaginário popular, da mídia de massa, dos currículos das Faculdades de Direito etc. Expressões como o "Palácio da Justiça", "Tribunal de Justiça", "Conselho Nacional de Justiça", "Dignidade da Justiça", dentre inúmeras outras, são completamente simbólicas e equivocadas. No Código de Processo Civil, publicado em 2015, com simples ferramenta de busca do "Google", é possível constatar que a palavra "justiça" é utilizada 171 vezes, o que não revela a melhor técnica, conforme Kelsen (2001), apenas para dar mais um exemplo. A Justiça é um conforto psicológico que pode ser alcançado por diversos instrumentos jurídicos e não jurídicos e, certamente, não apenas com a aplicação estrita da norma legal, esta última, como se sabe, sujeita à inúmeras interpretações possíveis nas mais variadas Instâncias jurídicas. (CAPPELLETTI; GARTH, 1988) 
Noutro giro, há, desde logo que ressaltar, importante atualização de nomenclatura que merece ser apontada. Melhor do que denominar de métodos "alternativos" de solução de conflitos, tem prevalecido que o termo técnico mais condizente seria métodos "adequados" de resolução de conflitos. A questão da terminologia gira em torno da possibilidade de a palavra "alternativo" dar ensejo ao entendimento de que método judicial seria o "melhor" (não alternativo - principal) e os outros apenas "alternativos" (secundários), o que efetivamente não é o que se quer dizer, nem muito menos tal conclusão se espelha na realidade empírica. Nesse sentido, em acréscimo, fala-se em Justiça Multiportas, esta consiste na integração de diversas formas de resolução de litígios, tanto de ordem judicial como extrajudicial. (BEDAQUE, 2011)

Os métodos adequados mais conhecidos de resolução de conflitos são: conciliação, mediação e arbitragem, estas podem se dar tanto no bojo de um processo judicial, como fora dele (judicial ou extrajudicial). Todos os estes, em maior ou menor medida, têm expressa previsão legal. Os arts. 165/175 do novo Código de Processo Civil, publicado em 2015, bem como a Lei no 13.140/15, trazem robusta regulamentação sobre os dois primeiros, enquanto a última, arbitragem, tem previsão legal na Lei no 9.307/96, bem como dispositivos esparsos em outras legislações, inclusive, também na codificação referida.

Por fim, aponta-se que em Brasil (2015) Lei nํ1․105, §3ํ do art. 3ํe expressamente determina que os métodos adequados de resolução de conflitos devem ser estimulados por todos os atores processuais, oportuna a transcrição:

A conciliação, a mediação e outros métodos de solução consensual de conflitos deverão ser estimulados por juízes, advogados, defensores públicos e membros do Ministério Público, inclusive no curso do processo judicial. (grifo nosso)

Há, ainda, como bem dispõe o trecho de lei acima mencionado, "outros métodos" de solução de litígios, para além daqueles previstos expressamente, existindo, dentre 
outros, a Justiça Restaurativa, que se estrutura em diversos aspectos humanos e legais, os quais também serão detalhados neste estudo.

Realizada esta breve, porém essencial introdução, desloca-se ao cerne, no qual será abordado o direito humano fundamental de acesso aos métodos adequados de resolução de conflitos, bem como a Justiça Restaurativa, com suas principais nuances, com conclusão, ao final.

\section{MEDIAÇÃO, CONCILIAÇÃO E ARBITRAGEM - DIÁLOGOS: APROXIMAÇÕES, REFLEXÕES E TÉCNICAS}

As formas adequadas de solução de conflitos envolvem fatores psicológicos determinantes para sua plena satisfação (FOUCAULT, 2013).

A diferença básica entre a Conciliação e a Mediação consiste no papel desempenhado pelo terceiro intermediador. O Conciliador interfere na relação processual, gerenciando as negociações, sugerindo propostas e apontando as vantagens e desvantagens, com o fim de alcançar o acordo entre as partes, enquanto que, na Mediação, o Mediador não influência às pessoas a chegarem à transação, simplesmente, através do diálogo estabelece pontes de comunicação entre as partes, com o fim de auxiliar na identificação dos interesses comuns, para que estas possam, por si sós, construírem a solução do problema por meio da

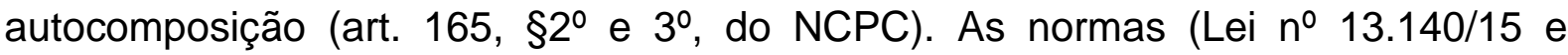
NCPC, dentre outras) trazem princípios, obrigações, deveres, garantias, prerrogativas e impedimentos àqueles que querem se dedicar à Conciliação e à Mediação (BRASIL, 2015).

À margem desta distinção técnica, é imperioso reconhecer que, na prática, elas podem se confundir, assumindo relevância especial os aspectos estruturais (físicos) e a técnica a ser utilizada. Sobre o primeiro aspecto, recomenda-se, para que as tratativas conciliatórias sejam mais bem conduzidas, que os espaços físicos sejam arejados, acolhedores, bem iluminados, mesas redondas e cores claras nos

RC: 94657

Disponível em: https://www.nucleodoconhecimento.com.br/lei/multiportas-erestaurativa 
ambientes. É importante atentar para a psicologia arquitetônica presente nos ambientes, isto é, da decoração ao prédio, tudo é importante para a condução das tratativas. Há verdadeiro diálogo interdisciplinar (BREITMAN; PORTO, 2001)

Há, ainda, as técnicas mais reconhecidas, a saber: escuta ativa, empatia, sessões individuais, liberdade de escolha de propostas, parafraseamento (ou recontextualização), ausência de pressa e resumo das tratativas. A seguir, apontase cada uma delas, reforçando, que elas atuam em conjunto, em rede e não se excluem mutuamente, e, seu sucesso, está muito relacionado com a experiência prática do intermediador. De forma sistemática para melhor compreensão, apresenta-se as mais reconhecidas (BREITMAN; PORTO, 2001):

a) Escuta ativa: consiste no momento de prestar atenção no que está sendo relatado pelos envolvidos no conflito, inclusive com expressão corporal positiva, afastando-se de pensamentos paralelos ou interrupções, evitando-se juízos de valor sobre aspectos externos (roupas, linguajar, tom de voz, olhar etc.), quando se escuta atentamente há maiores chances de se receber tratamento similar, o que aumentam as chances de composição.

b) Empatia: é imprescindível que durante o reconhecimento da situação narrada o intermediador demonstre sensibilidade com a questão trazida, não indiferença ou minimizando-a. Desde uma simples colisão entre veículos até complexos casos de guarda de criança, torna-se premissa necessária aceitar tais impasses como um "problema de fato" para a pessoa, ainda que, obviamente, ele não seja seu, do ponto de vista pessoal, por exemplo: o intermediador não têm filhos ou não se locomove por meio de veículos automotores.

c) Sessões individuais: se há constantes interrupções recíprocas durante a sessão, dificultando a comunicação, o entendimento do caso ou a proposição de soluções positivas, deve ser considerado ouvir os envolvidos separadamente, em locais distintos, e, até mesmo, se necessário, em horários diversos. Entendendo-se as versões de cada qual, de modo separado, é possível compreender a complexidade 
do litígio de forma mais ampla e detalhada, podendo-se, efetivamente, tentar alcançar as soluções.

d) Liberdade de escolha de propostas: a qualidade do acordo deve ser ponderada pelos envolvidos no conflito e não pelo intermediador. $O$ intermediador deve entender e respeitar o momento do ciclo de vida de cada um. Muitas vezes o desejo de fazer o acordo decorre da vontade de não ter que voltar para o Fórum, perdendo um dia de trabalho ou um momento de lazer, ou mesmo, ter que ver a outra parte novamente, tais circunstâncias devem ser objetivamente respeitadas. O conflito, em regra, transpõe o objeto colocado nos autos. Devidamente informados, deve-se prestigiar a solução encontrada pelos envolvidos.

e) Parafraseamento (ou recontextualização): tem por escopo extirpar carga emocional de eventual colocação dos envolvidos. É comum que os envolvidos narrem com dramaticidade a questão jurídica enfrentada, o que pode ofender o outro, sem que isso contribua efetivamente para a solução do impasse colocado. Os termos da lide devem ser entendidos objetivamente e analisados sob outra perspectiva (não subjetiva).

f) Interesses comuns: o conciliador deve partir de interesses comuns existentes entre os envolvidos. Nesta esteira, quando se debate uma pensão alimentícia por exemplo, um querendo reduzi-la e outro querendo aumentá-la há o interesse comum de bem-estar dos filhos, e a partir daí que se deve partir o raciocínio para a construção de uma solução positiva.

g) Ausência de pressa: é premissa elementar que as audiências tenham intervalos suficientes para sua realização. Não se pode ter pressa na busca da conciliação entre as partes, há um necessário tempo de maturação das propostas e reflexões dos envolvidos sobre os impasses colocados. As partes e advogados, normalmente, se encontram na audiência muito tensos, é preciso romper essas barreiras (por exemplo, braços cruzados, "cara amarrada" etc.). Não raras vezes um simples oferecer de um café ou de um copo d'água, já minimiza a beligerância, e os RC: 94657

Disponível em: https://www.nucleodoconhecimento.com.br/lei/multiportas-erestaurativa 
envolvidos se tornam mais dispostos às conversas construtivas, o que é fundamental para que se encontre uma solução para a controvérsia.

h) Resumo das tratativas: ao final, há redução a termo do que foi alcançado, excluindo-se o que não é necessário ao caso, os envolvidos se comprometem em cumprir o que foi acordado, em seguida, o acordo é homologado pela autoridade competente. Há possibilidade de conclusão de acordos em diversas esferas, como administrativa, judicial, extrajudicial (Defensoria Pública, Ministério Público etc.).

É imprescindível profissionais treinados para aplicação das técnicas mencionadas, não apenas no âmbito legal, isto é, de conhecimento técnico da norma jurídica aplicável, mas também no campo da psicologia, ou seja, um profissional interdisciplinar, resiliente, pronto para se adaptar ao que foi colocado rapidamente, atuando em verdadeiro diálogo de fontes. A psicologia é aplicada desde a construção física dos locais até a eventual preparação dos envolvidos para a solução transacional, com o importante acompanhamento subsequente. Tudo se comunica de forma intensa. O Direito é apenas um lado da dinâmica em apreço, há diversos outros que devem ser observados, atuando em rede, em diálogo construtivista constante.

A arbitragem, por sua vez, de ordinário, envolve grandes grupos econômicos, ela vem regulada, dentre outras, majoritariamente, pela Lei no 9.307/96. Deve envolver agentes capazes, prestando-se para dirimir conflitos relativos aos direitos patrimoniais disponíveis. A arbitragem pode se concretizar como de direito ou equidade[3], conforme ajuste entre as partes antes ou depois do litígio. A Lei no 13.129/15 expressamente autorizou a possibilidade de arbitragem no âmbito do Poder Público. Sempre houve grande controvérsia na aplicação da arbitragem no bojo da justiça consumerista e da justiça do trabalho, recente alteração na CLT (art. 507-A Lei no 13.467/17), no que se refere à Justiça do Trabalho, e a jurisprudência majoritária, tem admitido o instituto em ambas as áreas ${ }^{[4]}$, observados os requisitos legais. Os litigantes podem escolher as regras de direito aplicáveis, desde que não 
haja violação aos bons costumes e à ordem pública (BRASIL, 1996. Lei oํ 9.307 art. $2^{\circ}$, §1ㅇ; BRASIL, 2017).

Ademais, os envolvidos podem convencionar que a arbitragem se concretize com base nos princípios gerais de direito, nos usos e costumes e nas regras internacionais do comércio. Há centenas de Câmaras arbitrais, com regimentos próprios, custas e despesas específicas, tornando-se importante nicho de atuação para advocacia de elite (ARBIPEDIA, s.d).

Notem, todas as formas adequadas de solução de conflitos envolvem fatores psicológicos determinantes para sua proposição e solução, verificando-se verdadeiro diálogo de disciplinas, não apenas jurídicas, mas de outros ramos. As formas adequadas também são determinantes para a desjudicialização, em busca de uma nova forma de se "fazer Justiça", muito mais econômica, inteligente, prática e disruptiva, desjudicializando controvérsias que podem ser pacificadas em outras esferas sociais.

\section{JUSTIÇA RESTAURATIVA}

A Justiça Restaurativa se contrapõe à Justiça Retributiva, ou mesmo a Justiça Distributiva ${ }^{[5]}$, típica dos modelos ocidentais de Justiça, principalmente da civil law. O leading case ${ }^{[6]}$ ocorreu na cidade de Elmira, na Província de Ontário, no Canadá, em 1974, quando dois jovens, que vandalizaram 22 casas do próprio bairro, depois da sentença, passaram a frequentar a rotina daquelas famílias para verificar/conhecer os transtornos e as consequências de seus atos. Dois servidores viabilizaram as visitas que, não obstante alguma resistência do magistrado local, acabou ocorrendo, sendo registrada em notas (ZEHR, 2008).

A origem primária da Justiça Restaurativa decorre das rodas realizadas em comunidades indígenas, onde se buscava a solução de conflitos por meio da restauração da paz entre os envolvidos. As palavras-chave da Justiça Restaurativa são: amor, pertencimento e equilíbrio, seus valores fundamentais são: encontro,

Disponível em: https://www.nucleodoconhecimento.com.br/lei/multiportas-erestaurativa 
reparação, reintegração e inclusão. A Justiça Restaurativa tem sido praticada em países como Canadá, EUA, Reino Unido e Nova Zelândia, desde os anos 70 e 80, desembarcando no Brasil na década de 90 (GRECCO et al., 2014).

A corrente filosófica (Paul-Michel Foucault, Friedrich Nietzsche e Bento Espinosa dentre outros), apontam a aliança entre a Justiça Restaurativa e Filosofia Prática, permitindo a investigação dos diversos modos de construção do justo, como ele se dá nas relações humanas. Desse modo, muito além de uma metodologia prática, marcada pela técnica, a Justiça Restaurativa é um exercício filosófico que traz consigo a ampliação do conhecimento sobre si e sobre os outros, sobre as dores e sofrimentos promovidos pelo encontro e seus afetos; é um convite à invenção de um modo de vida ético que confronte os valores de uma cultura hegemônica (GRECCO et al., 2014).

A base psicológica ficou ao encargo de Eglash (1977, apud FABRIS; PERLIN, 2015), que por muitos anos trabalhou com detentos nos cárceres dos Estados Unidos, realizando amplo estudo sobre os efeitos deletérios da retribuição penal e sua baixa efetividade prática. $\mathrm{O}$ artigo denominado de Beyond Restitution: Creative Restitution, publicado em obra de coletânea: Restitution in Criminal Justice é considerado o marco psicológico do tema restaurativo.

Atualmente, as bases normativas da Justiça Restaurativa estão na resolução no 225/16 do Conselho Nacional de Justiça e na Resolução nº 2002/2012, antes resoluções no 26/1999 e 14/2000, da Organização das Nações Unidas. Em seguida a Resolução no 225/16 o CNJ publicou a Resolução № 300/2019, fixando prazo de 180 dias para que os Tribunais do País apresentassem no interregno de 180 dias o plano de implantação, difusão e expansão da Justiça Restaurativa, haja vista a forte resistência encontrada em alguns Tribunais.

A resolução traz importantes balizas conceituais aplicáveis à Justiça Restaurativa, oportuna a transcrição: 
Art. 1․ A Justiça Restaurativa constitui-se como um conjunto ordenado e sistêmico de princípios, métodos, técnicas e atividades próprias, que visa à conscientização sobre os fatores relacionais, institucionais e sociais motivadores de conflitos e violência, e por meio do qual os conflitos que geram dano, concreto ou abstrato, são solucionados de modo estruturado na seguinte forma:

I - é necessária a participação do ofensor, e, quando houver, da vítima, bem como, das suas famílias e dos demais envolvidos no fato danoso, com a presença dos representantes da comunidade direta ou indiretamente atingida pelo fato e de um ou mais facilitadores restaurativos;

II - as práticas restaurativas serão coordenadas por facilitadores restaurativos capacitados em técnicas autocompositivas e consensuais de solução de conflitos próprias da Justiça Restaurativa, podendo ser servidor do tribunal, agente público, voluntário ou indicado por entidades parceiras;

III - as práticas restaurativas terão como foco a satisfação das necessidades de todos os envolvidos, a responsabilização ativa daqueles que contribuíram direta ou indiretamente para a ocorrência do fato danoso e o empoderamento da comunidade, destacando a necessidade da reparação do dano e da recomposição do tecido social rompido pelo conflito e as suas implicações para o futuro.

Em seguida, trabalha princípios incidentes e legitimados ao pedido de aplicação da Justiça Restaurativa nos autos:

Art. $2^{\circ}$ São princípios que orientam a Justiça Restaurativa: a corresponsabilidade, a reparação dos danos, o atendimento às necessidades de todos os envolvidos, a informalidade, a voluntariedade, a imparcialidade, a participação, o empoderamento, a consensualidade, a confidencialidade, a celeridade e a urbanidade

\section{$(\ldots)$}

Art. $7^{\circ}$. Para fins de atendimento restaurativo judicial das situações de que trata o caput do art. $1^{\circ}$ desta Resolução, poderão ser encaminhados procedimentos e processos judiciais, em qualquer fase de sua tramitação, pelo juiz, de ofício ou a requerimento do Ministério Público, da Defensoria Pública, das partes, dos seus Advogados e dos Setores Técnicos de Psicologia e Serviço Social.

Parágrafo único. A autoridade policial poderá sugerir, no Termo Circunstanciado ou no relatório do Inquérito Policial, o encaminhamento do conflito ao procedimento restaurativo.

(grifo nosso)

$\mathrm{RC}: 94657$

Disponível em: https://www.nucleodoconhecimento.com.br/lei/multiportas-erestaurativa 
A ideia é afastar a vingança Institucional, ou mesmo, as denominadas Instituições democraticamente constituídas para este fim, restaurando-se os vínculos éticos e morais entre os envolvidos, perdidos em razão do conflito desmedido. Há diversos Municípios no Brasil que possuem leis que tratam especificamente da Justiça Restaurativa, como os Municípios de Barueri (Lei no 1.948/10), São José do Rio Preto (Lei no 12.977/18), Campinas (Lei nº 15846/19), Santos (Lei no 3371/17), dentre outros.

O objeto principal do litígio processual se altera, ou seja, busca-se sanar danos emocionais e materiais sofridos, colocando-se o agressor e vítima frente a frente para que ambos reavaliem suas próprias condutas e verdades. Há um resgate da ética entre os litigantes. Entende-se que o afeto e o conhecimento sobre o outro, pode levar a uma situação de empatia com o fato ocorrido, ou seja, ele se torna justificável sob certa perspectiva. É o caso típico do furto famélico, onde o agente subtrai coisa alheia móvel para saciar sua fome imediata, muitas das vezes é reconhecida a atipicidade da conduta em razão das circunstâncias verificadas (GRECCO et al., 2014).

O Facilitador, figura fundamental no círculo restaurativo, é considerado um construtor de novos contextos, um acompanhante participativo do grupo ou equipe em caráter temporário e provisório, um construtor de possibilidades de autoorganização do grupo durante todo o processo restaurativo. Sua postura representa o entrelaçamento entre emoções, saberes teóricos e metodologias voltadas à colaboração e criação de sinergia propícia ao surgimento de novas possibilidades de soluções e relacionamentos, tendo como foco principal a humanização das relações (BRASIL, 2016).

Neste ponto serão detalhadas um pouco mais da prática do círculo restaurativo. Há os objetos de centro de roda ou círculo, normalmente o centro é formado de maneira colaborativa, isto é, os participantes trazem objetos que entendem relevantes para aquele momento. Em regra, o Facilitador traz uma planta, que representa as origens 
comunitárias e indígenas do círculo, e literatura, livros, sobre o tema restaurativo. Abaixo dos objetos centrais é colocado um tapete ou outro objeto circular que "liga" (une) estas colaborações. Os objetos centrais também funcionam como refúgio aos olhos, para os participantes não serem obrigados e se entreolharem constantemente, caso não queiram ou consigam, por qualquer motivo. Existe, também, o "bastão de fala" que é passado pelo círculo, oportunidade onde a pessoa pode se expressar e o outro tem a oportunidade de ouvir. A comunicação é fundamental nos círculos. Ninguém é obrigado a falar, pode simplesmente passar o bastão. O bastão pode ser uma bola de borracha ou qualquer outro objeto, ele representa uma linha invisível de fala que está se formando entre os envolvidos. (GRECCO et al., 2014).

Há o pré-círculo, o círculo em si e o pós-círculo. No primeiro, verifica-se a possibilidade de aplicação da Justiça Restaurativa, enquanto no segundo existe sua efetiva prática, já no terceiro, ocorre uma avaliação daquilo que foi acordado e o que foi efetivamente alcançado, eventualmente, fixando-se novas diretrizes e metas, no caso de insucesso. Não há uma fórmula fechada, não se trata de um método circunscrito, mas sim de uma roda de diálogo com amplas possibilidades de confecção (GRECCO et al., 2014).

No início e ao final dos círculos ou rodas, há a possibilidade de uma cerimônia de abertura e outra de encerramento do encontro. Não há um tempo determinado para a realização das rodas, não obstante seja recomendável trabalhar com parâmetros para não haver um desgaste emocional desnecessário dos envolvidos. Conforme já dito, não há uma métrica cartesiana, a abertura ou encerramento podem ser desde uma reza ecumênica, um abraço coletivo ou uma simples selfie (GRECCO et al., 2014). 


\section{DIÁLOGOS: POSSIBILIDADES, APLICABILIDADES E LIMITES DOS MÉTODOS ADEQUADOS DE RESOLUÇÃO DE CONFLITOS}

De tudo que foi estudado até aqui, verifica-se a ampla aplicação dos métodos adequados (e não mais alternativos) de resolução de conflito no dia a dia da sociedade moderna. Os métodos trazem ao mundo do Direito verdadeiro diálogo com diversas áreas do conhecimento. Os métodos devem ser aplicados vastamente em litígios que envolvem a infância e juventude, idosos, mulheres e grupos vulneráveis em geral.

Há diversos limites aos métodos alternativos de solução de conflitos. Existe o limite legal, isto é, há casos em que a lei expressamente desautoriza a solução consensual, como no caso envolvendo interesses de menores (por exemplo, divórcio, adoção etc.), dentre muitos outros.

Existem barreiras culturais. Neste ponto, há relevante explicação. Muitas vezes o cidadão comum sequer tem conhecimento destes métodos, de sua efetividade e sua legalidade, preferindo o que o "juiz diz", como algo mais seguro. Há, também, barreiras de ordem econômica. Não raras vezes os Atores processuais, mormente o Advogado e o Ministério Público, estimulam o litígio no bojo do Poder Judiciário, por se tratar de fonte segura de renda, demonstrando "virilidade" na defesa do interesse do "Cliente", o que é visto pelo "senso comum" como algo virtuoso.

Também há limites de ordem política e corporativa. Os integrantes do Judiciário veem o processo e o "dizer o direito" como prerrogativa da Magistratura, supostamente imparcial e mais bem preparada para a solução da contenda. Nesta caixa, também se deve colocar o Parquet, capitão da legalidade extrema, profícuo em encarcerar grupos vulneráveis, mormente jovens de baixa renda (homens e mulheres negras de baixa renda), analfabetos estruturais e deficientes mentais. $\mathrm{Na}$ prática, o que se vê, é um Judiciário assoberbado de trabalho, resolvendo conflitos de forma rasa e com baixa efetividade social. A tutela antecipada (ou medidas 
liminares) torna-se o principal objetivo da demanda, para tentar salvaguardar a tutela do Direito.

Por tudo, pode-se constatar limites legais, econômicos, culturais, políticos e corporativos. Tais barreiras devem ser superadas por meio da educação em direitos, que deve acompanhar a formação escolar, profissional e pessoal.

\section{CONCLUSÃO}

Conforme apontado na introdução, o presente artigo tem como eixo central os métodos adequados de solução de conflito (conciliação, mediação e arbitragem), bem como a justiça restaurativa. Nesse diapasão, objetivou-se responder o que pode ser aperfeiçoado nos aspectos estruturais, processuais e humanitário, para fins de ampliação de seus efeitos práticos.

O Poder Judiciário precisa ser relido à luz dos métodos adequados de solução de conflito. É urgente uma releitura de gestão de sua atividade fim, isto é, a prestação jurisdicional. Qual serviço realmente devemos prestar à população? Não há razão nenhuma para inúmeros conflitos que envolvam crianças, adolescentes, família, empresas etc. ficarem ao encargo de uma sentença judicial imposta por um terceiro imparcial. Não há resolução efetiva, não poucas vezes, a sentença exarada não satisfaz o interesse de qualquer das partes. Há inúmeros recursos, muito desgaste emocional e financeiro para se alcançar um resultado de questionável efetividade técnica e prática.

É preciso abrir espaço para as partes, verdadeiros atores do conflito, para que busquem, por meio dos diversos métodos alternativos à solução de controvérsia, a melhor forma de solucionar o impasse colocado. Não há razão para o monopólio da Justiça, a Justiça, conforme já dito, é um conceito relativo, com significado inconsistente. É de suma importância que o paternalismo judicial seja substituído por um trabalho em rede, quando necessário, afastando-se da figura do Juiz que fica dando "bronca" nas partes, advogados etc., seja durante a demanda, seja em atos 
específicos, como nas audiências, seja por meio de manifestações. Trata-se de ciclo de violência institucional estrutural insustentável, muito caro aos cofres públicos, sem qualquer efetividade prática e emocionalmente irracional.

Ao longo deste texto, notou-se que Justiça multiportas traz diversos métodos de resolução de conflitos para além daquele realizado pelo Poder Judiciário. No âmbito do Poder Judiciário é possível a aplicação de todos eles antes ou durante o processo, mas, o melhor seria que o Judiciário fosse utilizado apenas em conflitos em que não exista qualquer possibilidade de consenso entre as partes.

As figuras do Advogado[7], Defensor Público[8], Ministério Público[9] e Juiz ${ }^{[10]}$, personagens típicos de um litígio intenso, marcadas historicamente pela luta constante e a vitória a qualquer preço, assumem especial relevância nesta nova "educação jurídica" para a Justiça Multiportas em verdadeiro diálogo de fontes. A Justiça Multiportas apenas poderá crescer e se desenvolver se essas importantes figuras reconhecerem a importância social destes métodos, deixando de lado interesses corporativos, políticos e econômicos (por exemplo, honorários contratuais, sucumbenciais, ad exitum etc.), que muitas vezes ditam a dinâmica da propositura da demanda judicial.

A Justiça Restaurativa representa o futuro da dinâmica do conflito, em busca da pacificação social e da tão almejada celeridade processual (art. 5o, LXXVIII, CF/88). Por fim, defende-se, a aplicação da Justiça Restaurativa para conflitos envolvendo a área da infância e juventude, impasses escolares, condominiais, associativos empresariais ou não, penais, onde não haja violência e grave ameaça, e trabalhistas, bem como no âmbito público. Infinitas são as possibilidades. É possível também a concomitância do processo restaurativo em conjunto com o processo tradicional, visto que, muitas vezes, diante do sistema legal, o processo judicial ou administrativo são inafastáveis, o que, por si só, é um contrassenso. 
O amplo diálogo entre os ramos do Direito e as demais disciplinas (psicologia, antropologia etc.) deve ser estimulado e prestigiado, buscando-se soluções a partir dos próprios envolvidos e não a partir do sistema de Justiça tradicional.

\section{REFERÊNCIAS}

ARBIPEDIA, Câmaras arbitrais: regulamentos, custas e listas de árbitros. s.d. Disponível em: <https://www.arbipedia.com/conteudo-exclusivo/camaras-arbitraisbrasileiras.html>.

BEDAQUE, J. R. dos S. Direito e processo. 6ª edição. São Paulo: Malheiros, 2011.

BRASIL. CONSTITUIÇÃO DA REPÚBLICA FEDERATIVA DO BRASIL DE 1988. Disponível em: <http://www.planalto.gov.br/ccivil_03/constituicao/constituicaocompilado.htm>.

BRASIL. RESOLUÇÃO 225, DE 31 DE MAIO DE 2016. Disponível em: <https://atos.cnj.jus.br/files/resolucao_225_31052016_02062016161414.pdf>.

BRASIL. LEI № 13.467, DE 13 DE JULHO DE 2017. Disponível em: <http://www.planalto.gov.br/ccivil_03/_ato2015-2018/2017/lei/l13467.htm>.

BRASIL. LEI № 13.105, DE 16 DE MARÇO DE 2015. Disponível em: <http://www.planalto.gov.br/ccivil_03/_ato2015-2018/2015/lei/l13105.htm>.

BRASIL. LEI № 9.307, DE 23 DE SETEMBRO DE 1996. Disponível em: <http://www.planalto.gov.br/ccivil_03/leis/19307.htm>.

BREITMAN, S.; PORTO, A. C. Mediação familiar: uma intervenção em busca da paz. Porto Alegre: Criação Humana. 2001.

CAPPELLETTI, M.; GARTH, B. Acesso à Justiça. Tradução de Ellen Gracie Northfleet. Editora: Fabris, Porto Alegre, 1988. 
FABRIS, G. M.; PERLIN, E. J. Justiça Restaurativa e sua possível aplicabilidade no Brasil. $3^{\circ}$ SIMPÓSIO, COOPEX. 2015. Disponível em: $<$ https://www.fag.edu.br/uplo ad/contemporaneidade/anais/55954ab92e172.pdf>. Acesso em: 27/04/21.

FOUCAULT, M. A Verdade e as Formas Jurídicas. Rio de Janeiro: Nau, 2013.

GRECCO, A.; et al. Justiça Restaurativa em ação: práticas e reflexões. São Paulo: Dash, 2014.

KELSEN, H. O que é Justiça? a justiça, o direito e a política no espelho da ciência. Tradução: Luís Carlos Borges, 3ª edição. São Paulo: Martins Fontes, 2001.

ZEHR, H. Trocando as Lentes. São Paulo: Palas Athena, 2008.

\section{APÊNDICE- REFERÊNCIA NOTA DE RODAPÉ}

3. Não há significado unívoco para o termo equidade, parte significativa da doutrina defende tratar-se da aplicação da justiça no caso concreto, outros, a aplicação da razoabilidade e proporcionalidade no caso concreto. Como se pode observar, tratase da substituição de um termo geral por outros dois termos gerais sem qualquer baliza objetiva para o operador da norma.

4. REsp 659631/BA (Direito do Trabalho) e REsp 1854483/GO (Direito do Consumidor)

5. Esses conceitos têm por base as doutrinas de Platão e Aristóteles.

6. Caso condutor ou referência.

7. Advogado deve ser entendido como advogados públicos (procuradores municipais, estaduais, federais), privados (OABs), dativos etc. 
8. Ministério Público deve ser entendido no âmbito de todo o Ministério Público Federal e Estaduais, com sua respectiva hierarquia.

9. Defensoria Pública deve ser entendida no âmbito de toda a Defensoria Pública Federal e Estaduais, com sua respectiva hierarquia.

10. Juiz deve ser entendido como toda a Magistratura Federal e Estadual, inclusive, Desembargadores, Presidentes e Corregedores (CNJ etc.).

Enviado: Julho, 2021.

Aprovado: Agosto, 2021 